\title{
INFLUENCE OF CONSTRUCTION OF LOGISTICS CENTRE ON TRANSPORT IN VIENNA
}

\author{
Radek Dvořáček, Kateřina Víchová
}

\begin{abstract}
The aim of this paper is to find out how the construction of a new logistics centre in the vicinity of the A21 and B12 interchange will affect transport in Vienna. Transport in the city and near logistics centres plays a vital role. Today, a significant amount of goods is transported. Transport infrastructure is used for this purpose, where transport infrastructure represents a significant part. It is essential to note that the increasing number of goods transports may create transport problems in infrastructure. Thanks to the simulations, these problems could be detected and optimization could be proposed and verified again. In the paper firstly, there is introduced the current state of the traffic in the selected part of the Vienna. Secondly, there is introduced the software, which is used in this paper. There was selected the software for the microscopic traffic simulation - PTV Vissim. Next, there are presented the results of this simulation. Based on this simulation, there are shown potential traffic problems caused by the construction of this centre. Transport problems caused by the development of a logistics centre are not severe.
\end{abstract}

Keywords: Logistics, A21, Vienna, Transportation, PTV Vissim, infrastructure

\section{INTRODUCTION}

In this work, an example simulation of the A21 and B12a off-road intersections located in the outskirts of Vienna will be solved. In the first part of this work will be given a detailed description of the roads, including maps of the streets. Subsequently, the work will be devoted directly to the intersection of the roads. In the last part, the simulation of this grade crossing in the PTV VISSIM program will be carried out first for the normal state of operation and then for the process with the logistics centre, which will be situated on Europaring. Given the current need for rapid transport of goods and materials, it is necessary to build logistics centres to ensure this flow of products and materials. The aim of this paper is to find out how the construction of a logistics centre will affect traffic on the interchange in Vienna. Due to the direct connection of the logistics centre to the motorway, it is not expected that the traffic density on the section will be increased too much.

\section{METHODOLOGY}

PTV Vissim simulation program is used to find out how the construction of a logistics centre will affect traffic. Testing in reality would be too costly; simulation is used to solve this problem. The transport system is under intensive investigation through modelling and simulation. The simulation model describes the concrete abstractions of the proposed and is built on understanding the policy. The first component is the data that will be used on the model, i.e., traffic statics and information. The second component is a simulation algorithm that calculates the movement of vehicles (cars or anything else, such as trams, bicycles), with their specific acceleration and deceleration. The third component of visual simulation is motion animation and simulation results. The last part is verification (Pak, 2010). Nowadays, it is the simulations that are most suitable for solving this problem, because testing, in reality, would be too expensive. Logistics centres are best placed as close as possible to the main traffic arteries, 
which is currently happening. Thanks to this location, it is possible to serve a large number of customers in various places without any problems and does not affect the surrounding area.

\section{CURRENT STATE}

The next part describes in detail the roads that this work covers. In the first place is described the most crucial highway, which is part of the grade crossing, namely the highway A21, then the road B12 and ultimately directly grade crossing these roads.

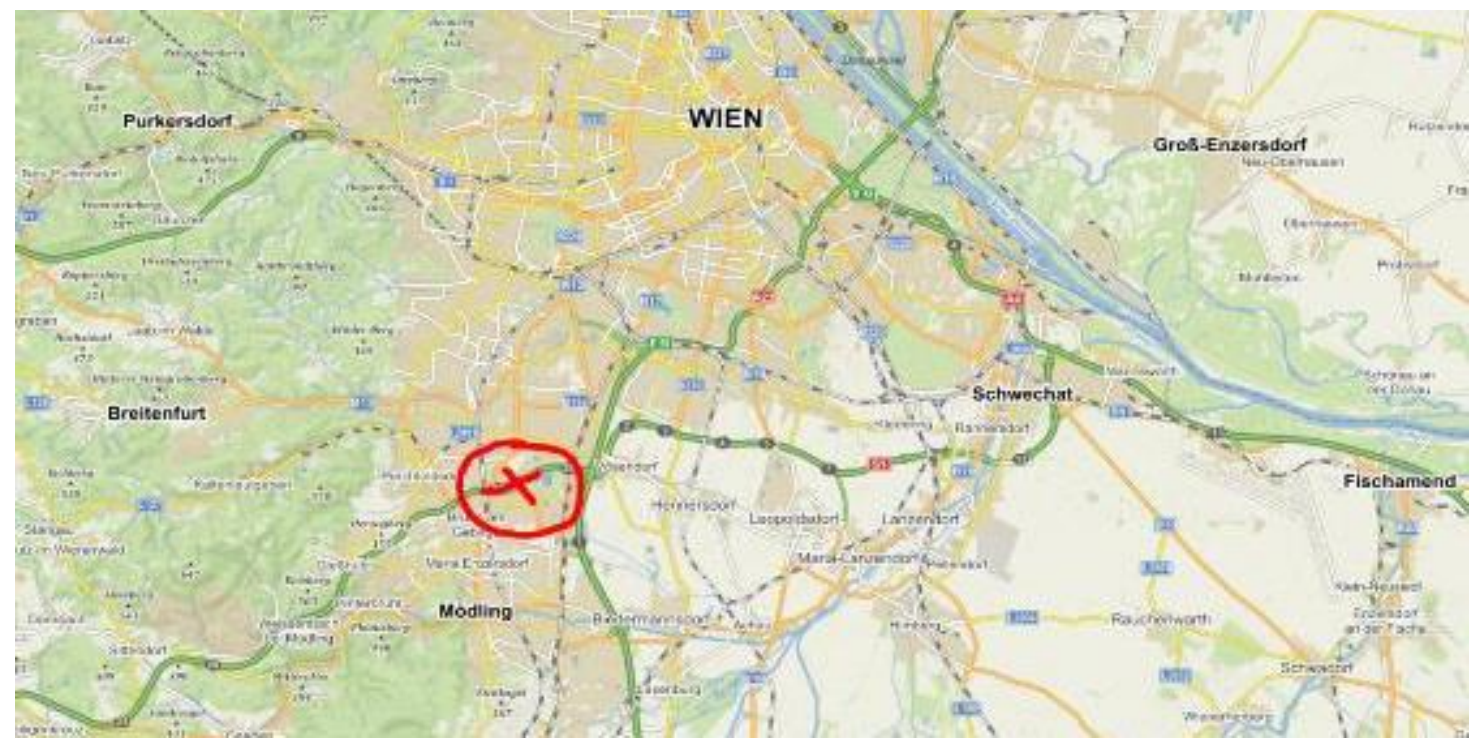

Fig. 1 - Location of grade crossing. Source: Mapy.cz (2019)

\subsection{Motorway A21}

Wiener Außenring Autobahn A21 in German is a motorway in Austria and is part of the European Route 60. The A21 motorway connects the western A1 motorway, the most significant Austrian motorway linking Vienna and Salzburg, at the Steinhäusl junction with the southern A2 motorway Vienna to the Italian border, at the Vösendorf junction, where it opens to the unfinished Vienna S1 circuit. In the future, the A21 motorway, in conjunction with other motorways, namely the S1, A22, S5, S33, and A1, should form the so-called Regionenring. The entire "Regionenring" should be about $195 \mathrm{~km}$ long, and about $175 \mathrm{~km}$ has been completed. Upon completion, "Regionenring" will become the second-longest ring road after Berlin's Bundesautobahn $10(196 \mathrm{~km})$ and before the London M25 (188 km). (Asfinag, 2019)

\subsection{Brunner Straße B12}

Brunner Straße is a $13.6 \mathrm{~km}$ long primary road B in Vienna, the provincial road B in Lower Austria, and the former motorway. The Brunner Straße leads from Mödling via BrunnamGebirge to Vienna, where it joins the B 221. In Vienna, the B 12 has the names Brunner Straße, Breitenfurter Straße, and Eichenstraße. The Brunner Straße is divided into two branches. The B12a leads from Perchtoldsdorf, crosses the A21 motorway, continues through Brunn am Gebirge, and finally connects to the B17 Wiener Neustädter Straße. The second branch of the B12b, the so-called Sageergasse, runs between Breitenfurter Straße and Altmannsdorfer Straße. B12b brings traffic to the A23 motorway, which is the busiest road in Austria, with 170,000 vehicles passing in 24 hours. (Asfinag, 2019) 


\subsection{Elevation crossing of the A21 motorway and B12A}

The elevated crossing of the A21 motorway and the B12a road is located east of the town of BrunnamGebirge, in the province of Lower Austria and near the border with Vienna. This crossing mainly serves to connect the A21 and B12a roads mentioned here. Furthermore, this crossing serves as an arrival to Europaring, where there are various companies and hotels. In addition, the ultimate and essential purpose of this crossing is the arrival of vehicles from the A21 motorway to the already mentioned town of Brunn am Gebirge. (Asfinag, 2019)

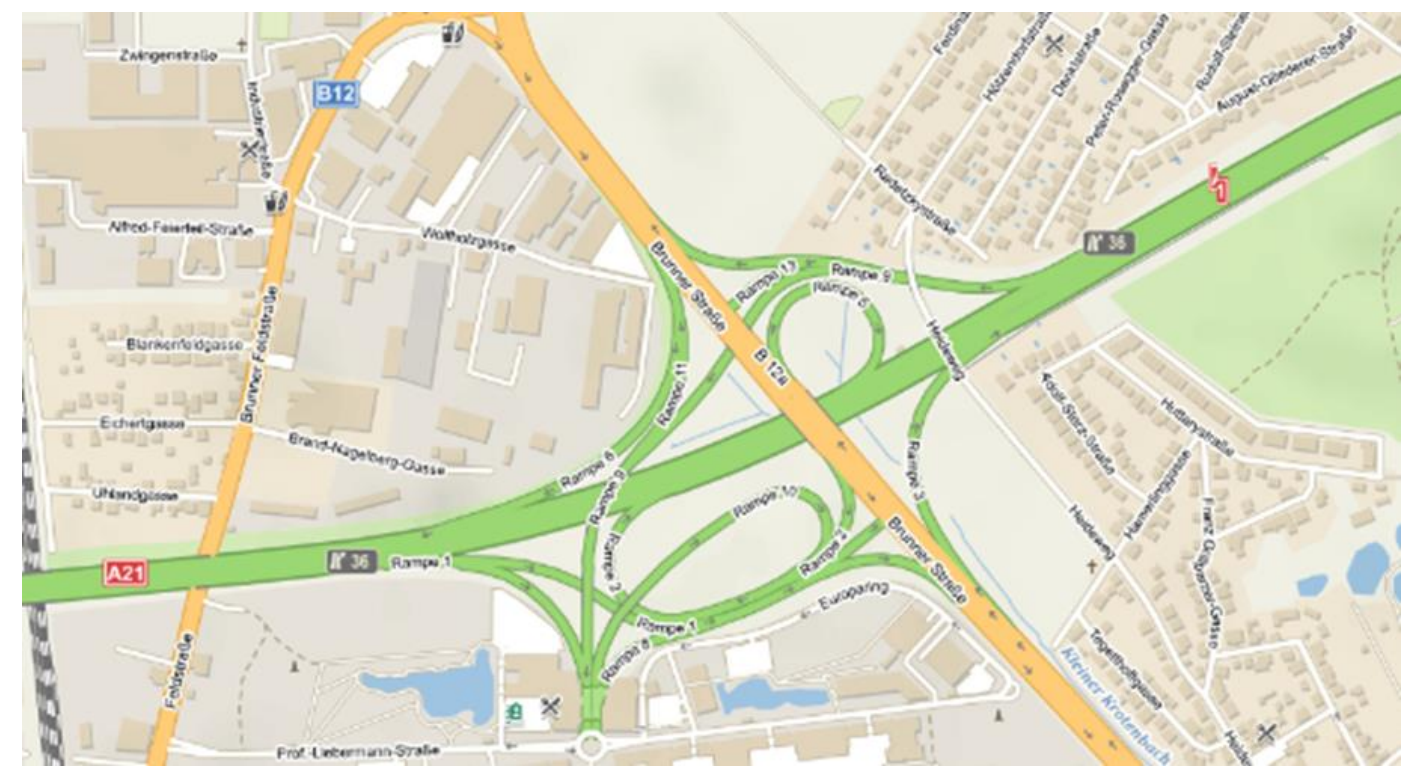

Fig. 2 - Map background for crossing A21 and B12a. Source: Mapy.cz (2019)

This grade crossing is very complex. It consists of 13 so-called Ramps, which are used to connect the surrounding roads, and due to the use of connecting lanes, there is no excessive formation of columns, and traffic is thus smooth. However, there are also two traffic lights, both when connecting Ramp 1 to Brunner Straße (B12a) and Ramp 13 to Brunner Straße. At the exit of Europaring, there is also a roundabout. (Asfinag, 2019)

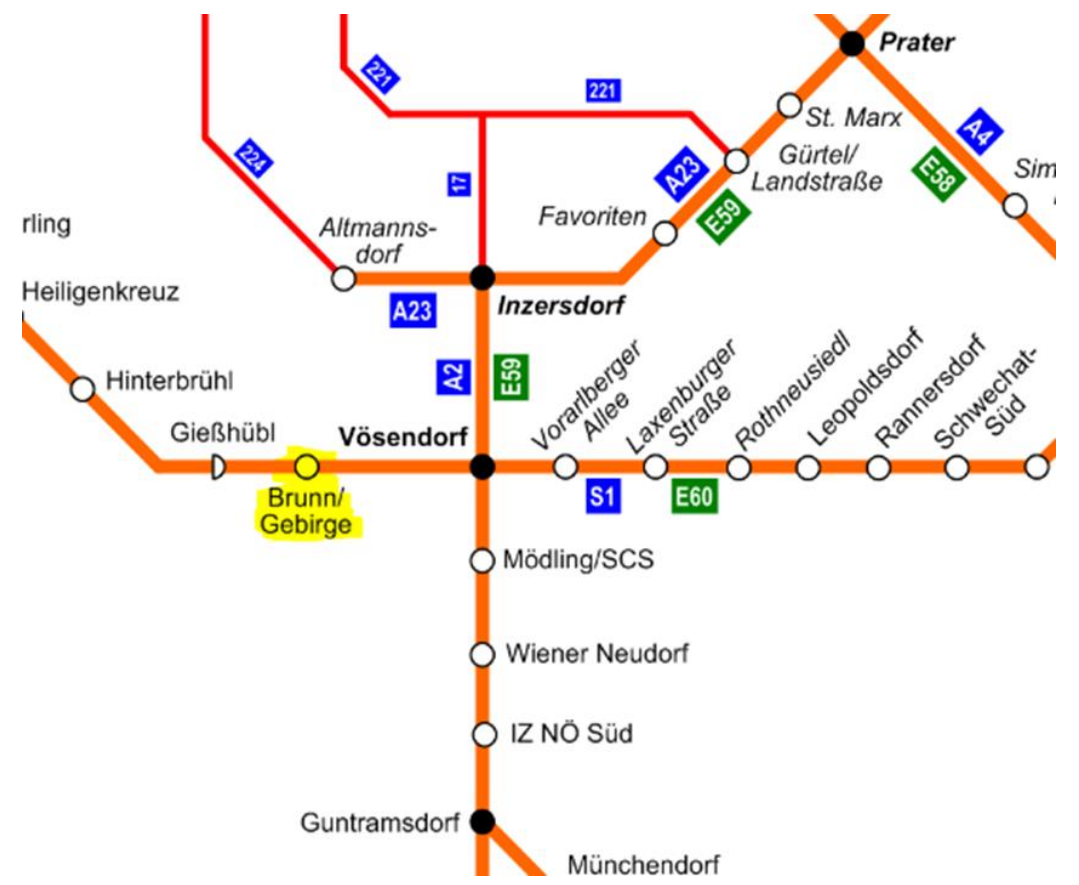

Fig. 3 - Location of crossings in the road network. Source: Wikipedia (2019) 


\section{RESULTS}

The next part includes simulation results. The results are divided into two chapters, before the construction of the logistics centre and after the development of the logistics centre. The two simulations were then compared, and the change evaluated.

\subsection{Simulation of the current state of grade crossing}

When creating a simulation in PTV VISSIM, it was found that traffic lights did not affect traffic in any significant way. Still, there would be a potential to improve the situation, provided Ramp 1 and 13 were rebuilt to connect via the connection strip on the B12a road. There are no significant delays on other roads, and traffic is smooth. Due to the location of this crossing, in urban areas, the maximum speed allowed on the A21 motorway is $80 \mathrm{~km} / \mathrm{h}$ and $70 \mathrm{~km} / \mathrm{h}$ on the B12a road. On most ramps, the speed is not further adjusted, which means a maximum speed of $80 \mathrm{~km} / \mathrm{h}$. The traffic density in the VISSIM simulation was verified through the traffic density map implemented in Google Maps.

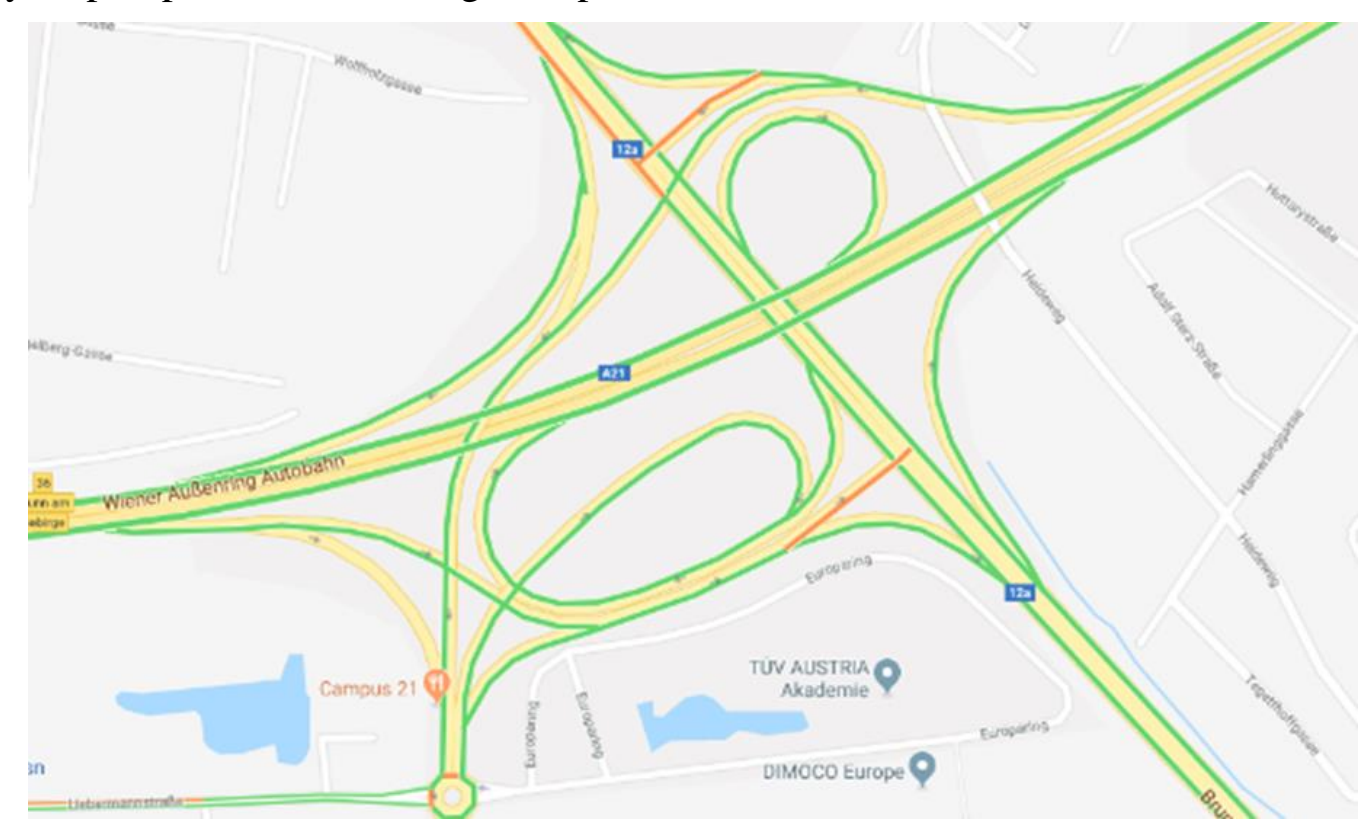

Fig. 4 - Traffic density. Source: Google Maps (2019)

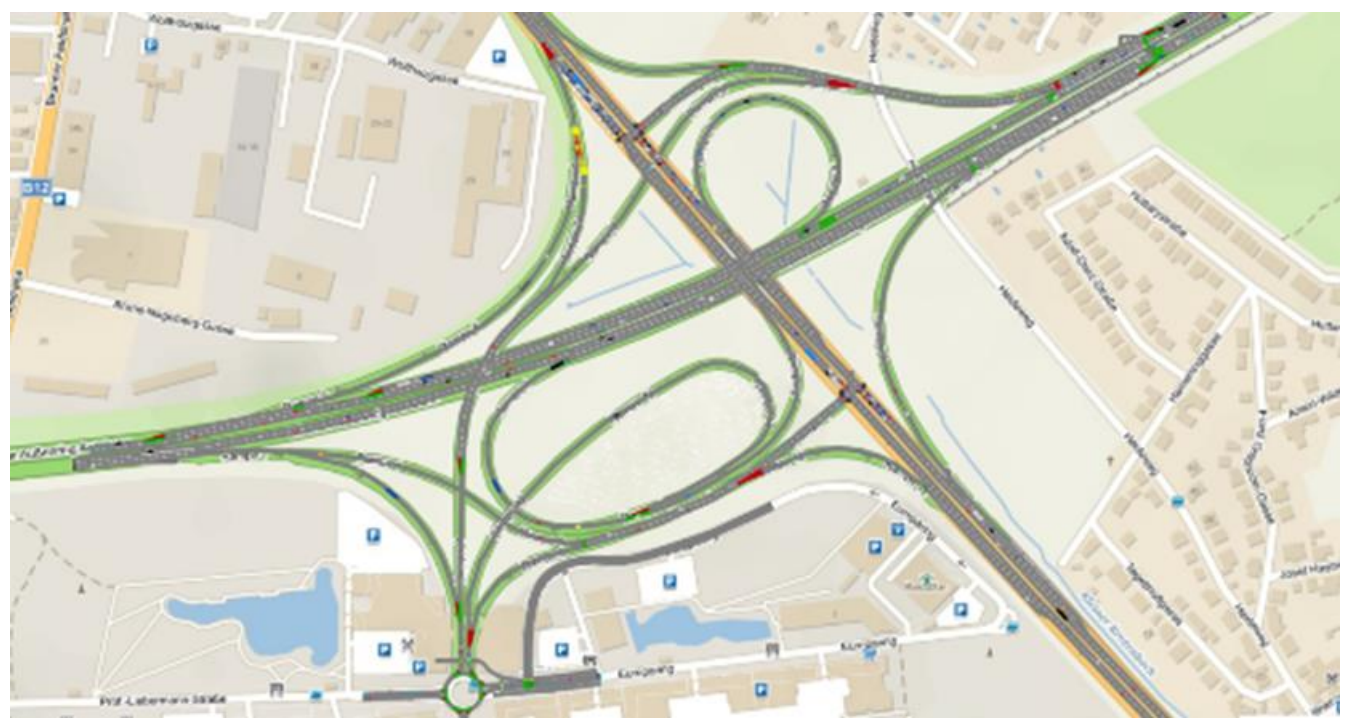

Fig. 5 - General view of crossing in Vissim. Source: own research 


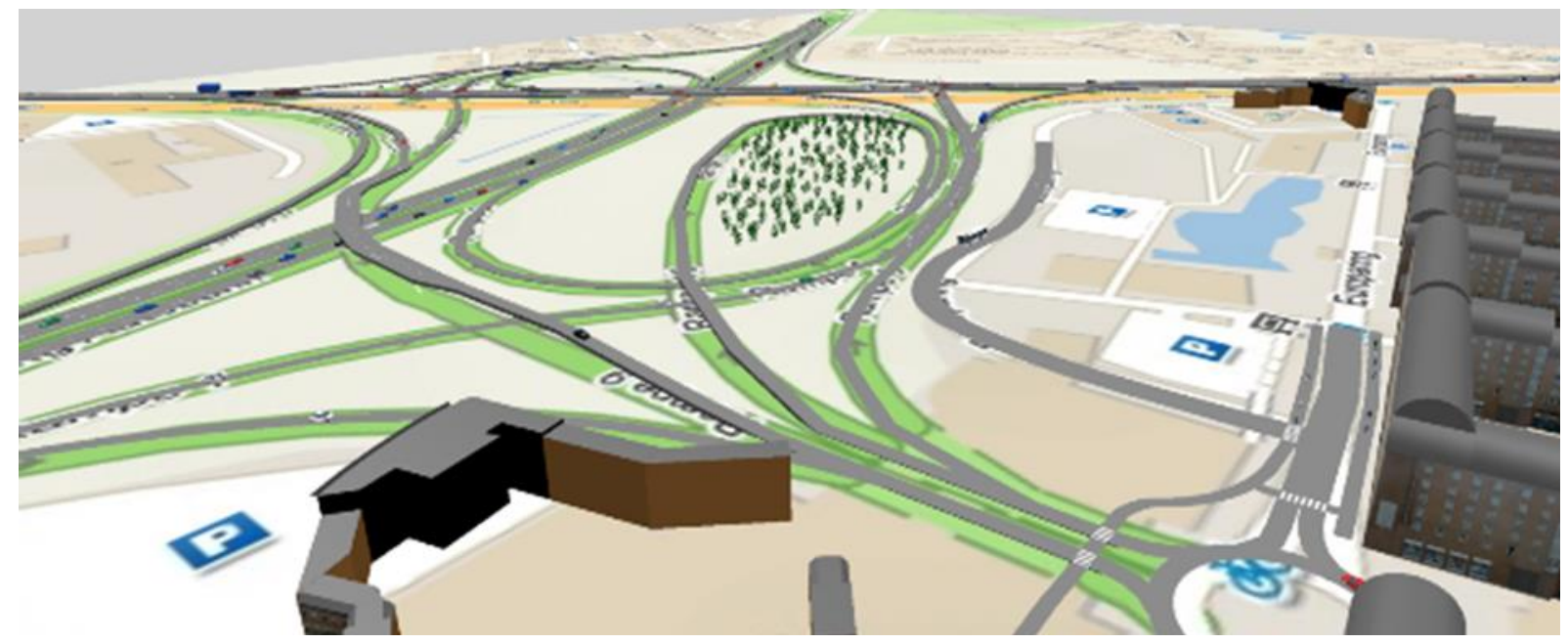

Fig. 6 - General view of the crossing from the northwest. Source: own research

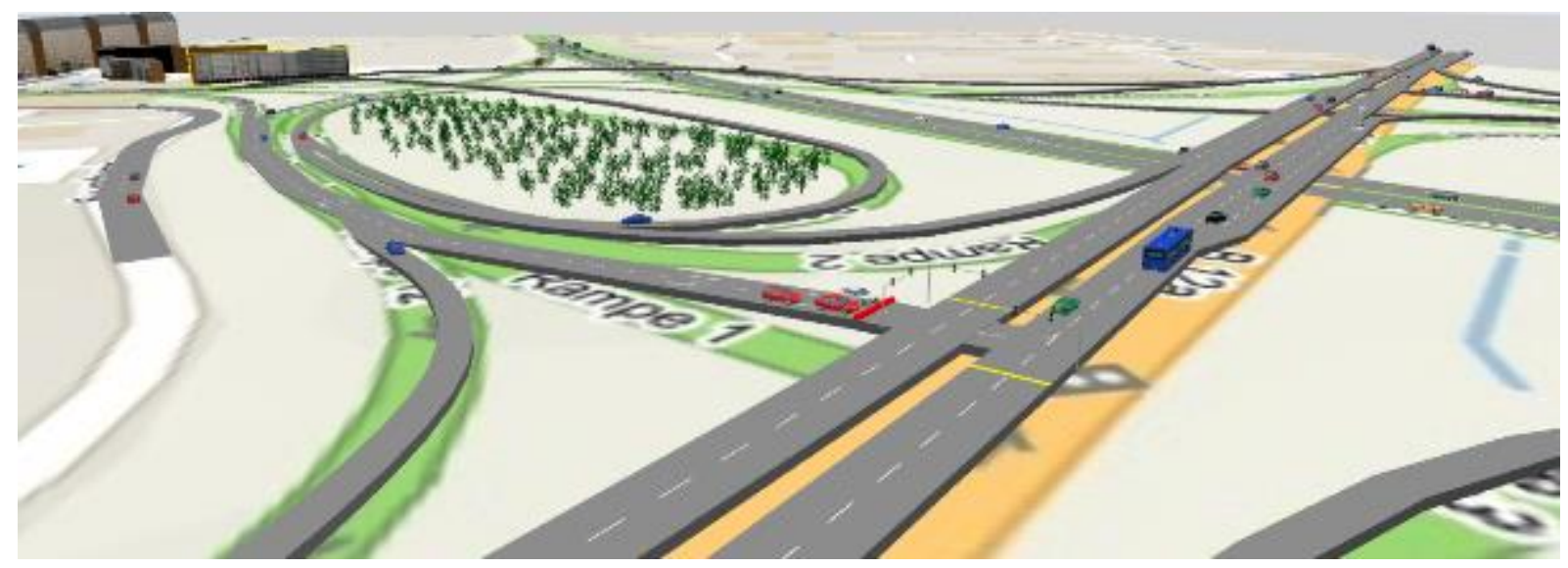

Fig. 7 - Detail of traffic lights. Source: own research

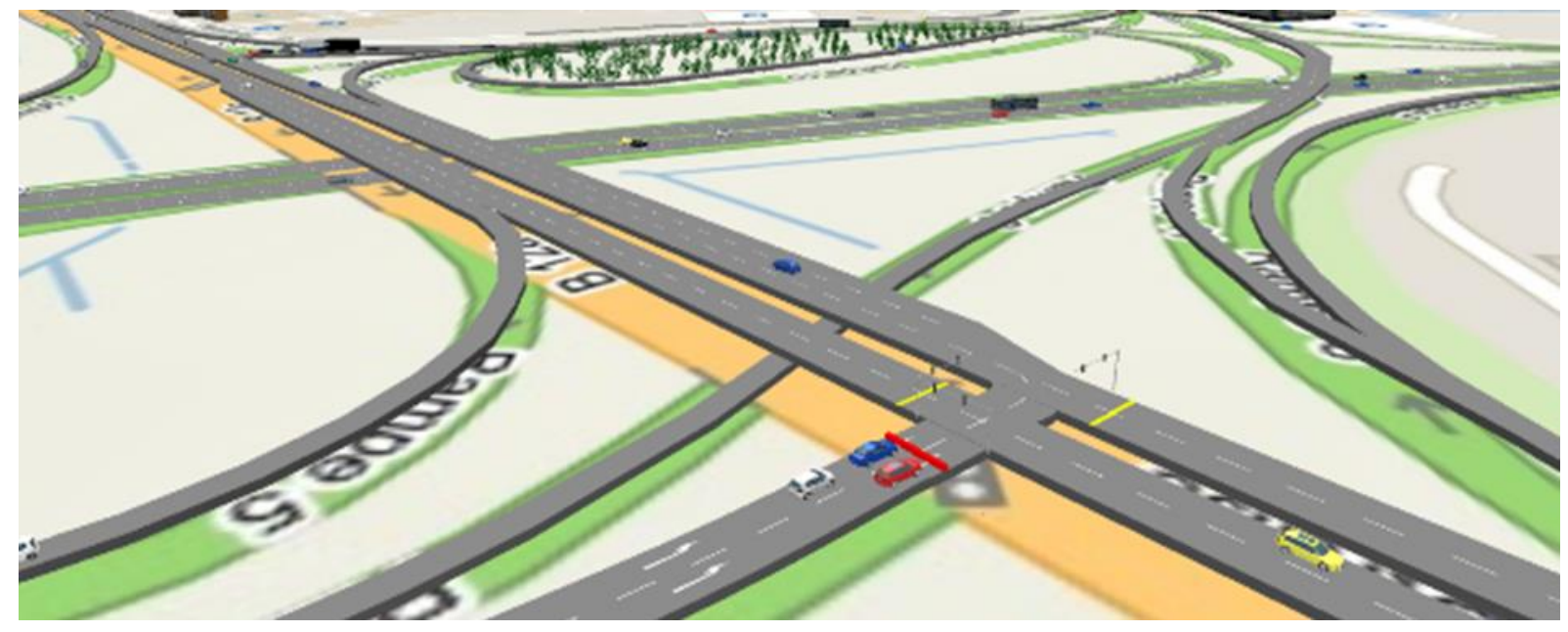

Fig. 8 - Flyover detail. Source: own research 


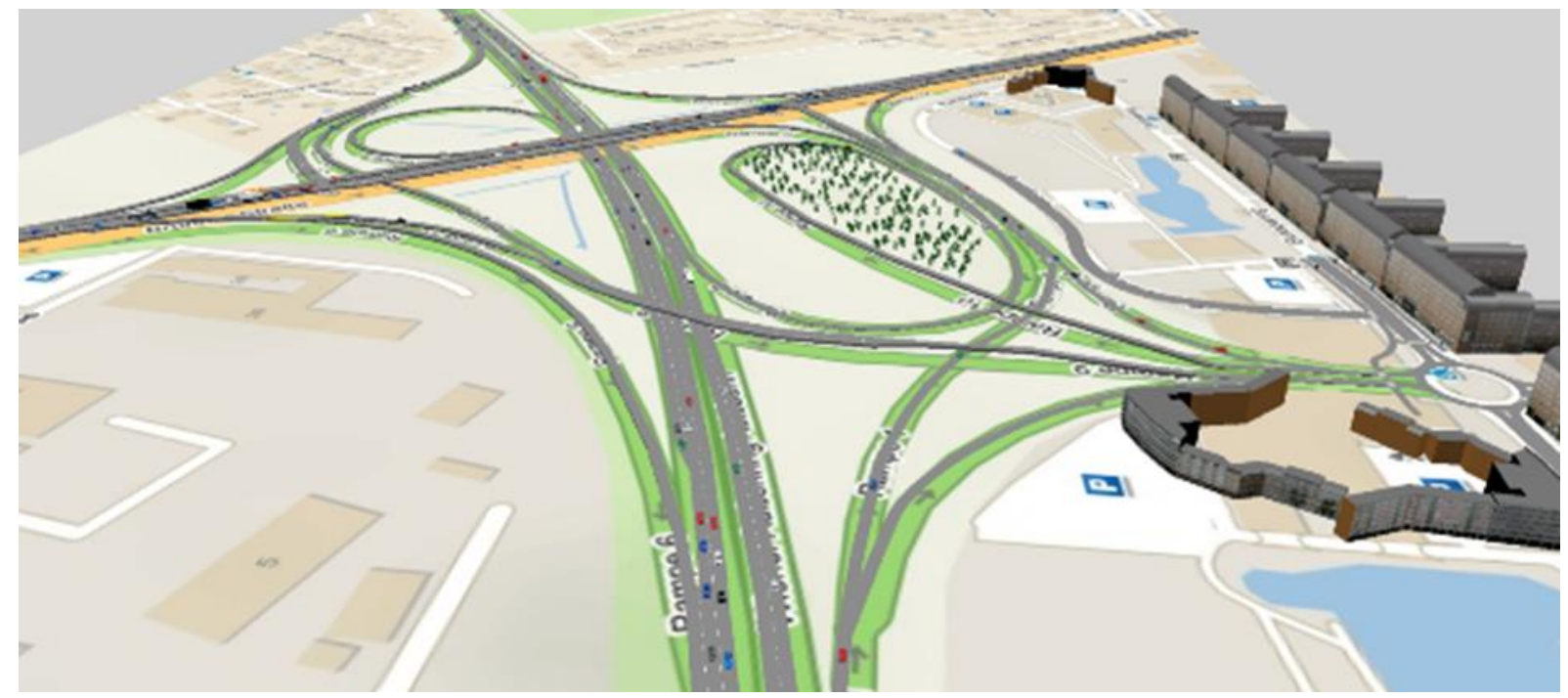

Fig. 9 - General view from the west. Source: own research

\subsection{Simulation of grade crossing with logistics centre}

The central task of this work was to find out what influence the construction of a logistics centre will have on traffic at a selected intersection. In this particular case, the logistics centre was located at Europaring. The traffic density was set at 300 LKW vehicles per hour, which is a relatively high value, but suitable for visualizing any traffic problems. Due to the author's knowledge, however, only communication with LKW transport from the warehouse was added, but not the arrival of LKW vehicles to the logistics centre. Despite the relatively oversized value of traffic from the logistics centre, no significant deterioration in transit was observed at the monitored intersection. Insignificant delays can occur at places controlled by light signalling devices and in front of a roundabout near the distribution warehouse.

According to the author, no or relatively low traffic deterioration is mainly because the logistics centre is located just at this grade-separated crossing, which means excellent accessibility to the main roads, in this case, the A21 motorway and the Brunner Straße B12a. It is the worsening traffic and availability on the main routes that are one of the essential points in the construction of the logistics centre. This warehouse location fulfils both of these aspects.

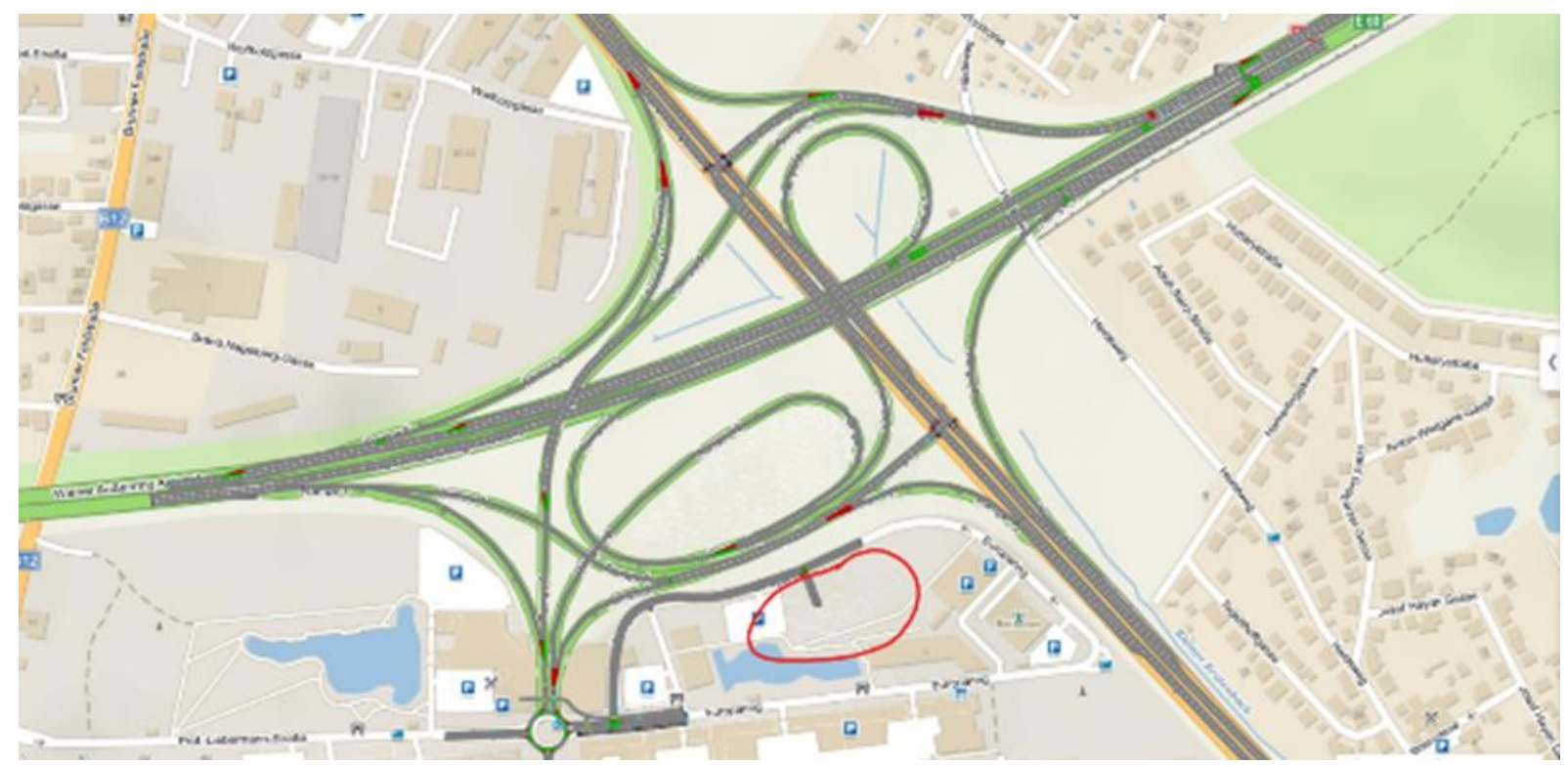

Fig. 10 - Location of the logistics centre. Source: own research 


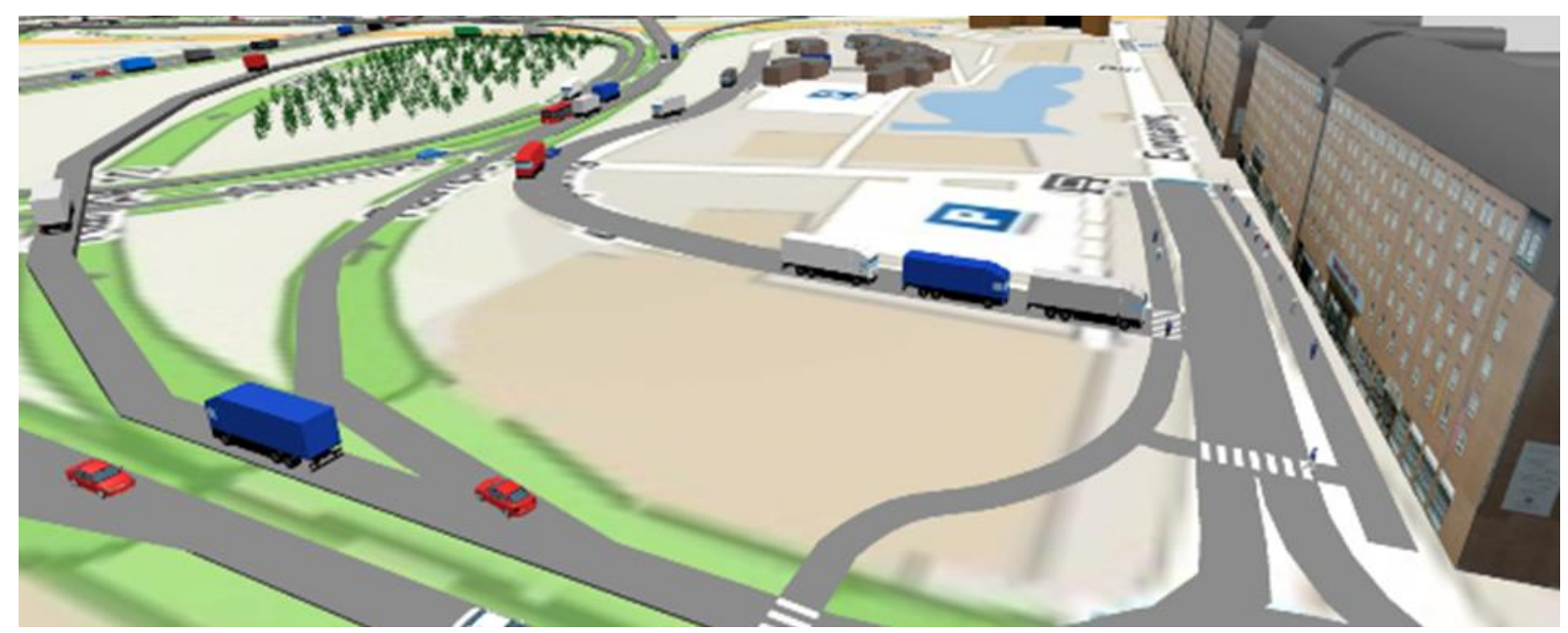

Fig. 11 - LKW vehicles leaving the distribution warehouse. Source: own research

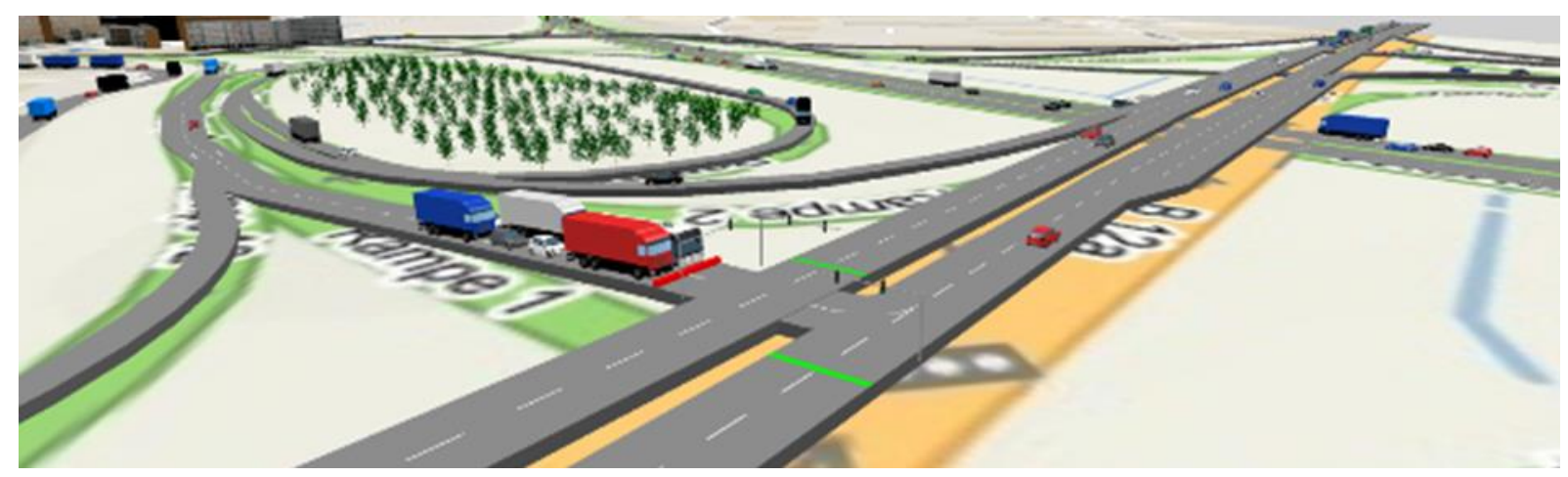

Fig. 12 - Detail of traffic lights with LKW vehicles. Source: own research

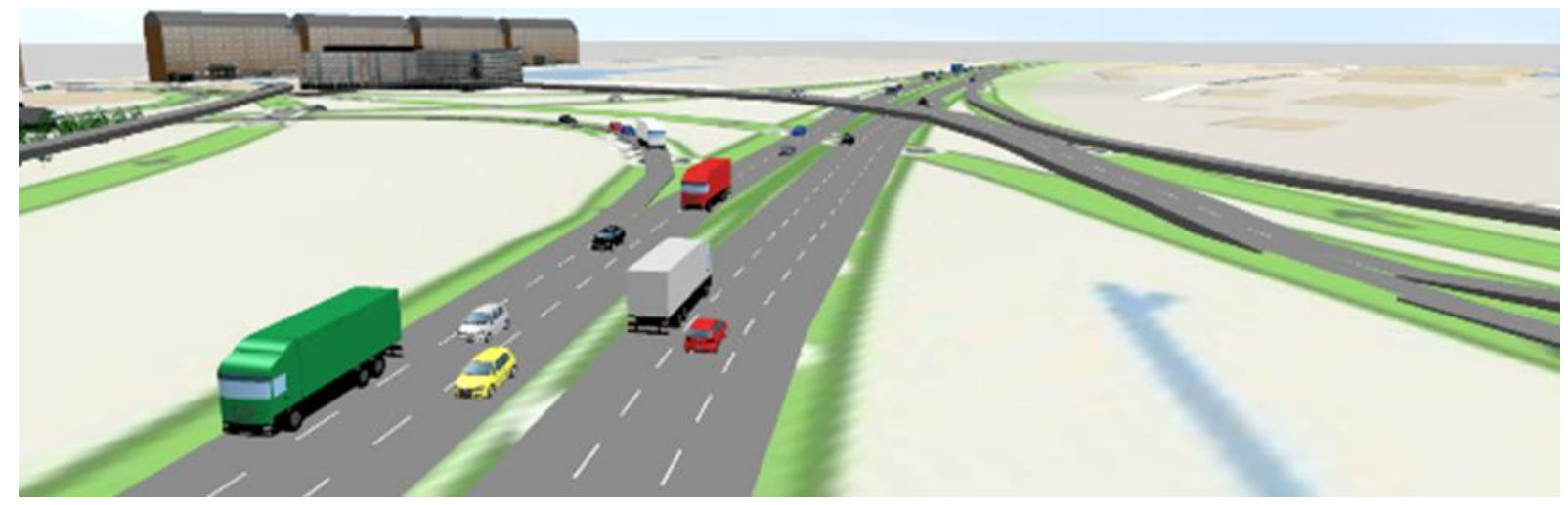

Fig. 13 - Detail of exit of LKW vehicles on highway. Source: own research

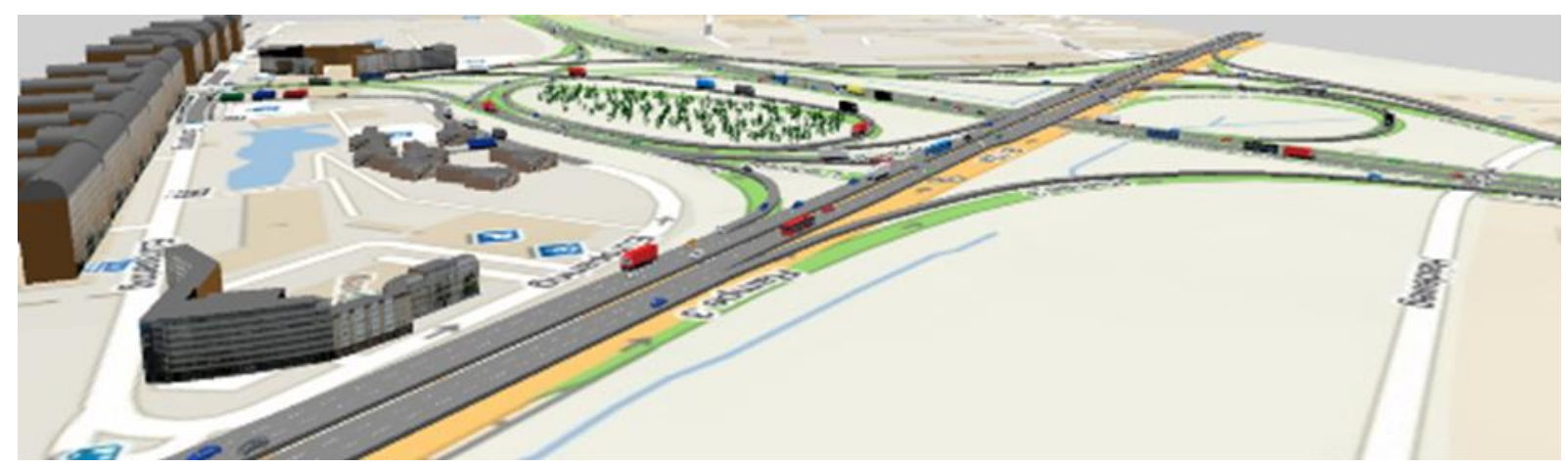

Fig. 14 - A view of a variant with a logistics centre from the southeast. Source: own research 


\section{DISCUSSION AND CONCLUSION}

In this paper, the intersection of A21 and B12a roads was solved, of which A21 is a motorway, and B12a is the main road. In the first part, the streets were described in detail, including their interest in the Austrian motorway and road network. The location of this crossing and both roads on the future Vienna circuit, also called the Regionenring, was discussed in this section. Subsequently, the crossing was modelled in the PTV VISSIM program to correspond as accurately as possible to the actual situation. Due to the unavailability of data, the traffic density was chosen according to the best knowledge and conscience of the author, so that it was as accurate as possible. According to this simulation, critical points were discovered, and then a better solution to these crisis points was proposed, but this was not simulated since it was not the subject of this work.

The main task of this work was to find out the change in traffic density after building a logistics center. After a detailed analysis of the possible locations of this warehouse, the most suitable option was the warehouse location option at Europaring. This location was chosen for availability on all critical roads. After simulating this variant, it was found that the traffic of LKW vehicles affected traffic on the crossing only minimally, and therefore, there is no risk of traffic collapse. Observable delays only occur at the roundabout leading from Europaring, which, however, due to the low traffic density at Europaring, does not consider the author a significant problem. All this work contains many pictures from the VISSIM program, which were chosen to reflect the traffic situation on the selected interchange accurately. The paper is also supplemented by map data for the exact location of this grade crossing.

\section{References}

Asfinag (2019). Retrieved from https://www.asfinag.at/

Google Maps (2019). Retrieved from https://maps.google.com/

Mapy.cz (2019). Retrieved from https://www.mapy.cz/

Pak, H. C. (2010). Simulátor dopravní sitě. Praha: Univerzita Karlova.

Wikipedia (2019). Retrieved from https://de.wikipedia.org/

\section{Contact information}

\section{Radek Dvořáček}

Tomas Bata University in Zlín, Faculty of Logistics and Crisis Management Studentské nám. 1532, 68601, Uherské Hradiště, Czech Republic

E-mail: r1_dvoracek@utb.cz

ORCID: 0000-0001-7446-8448

\section{Kateřina Víchová}

Tomas Bata University in Zlín, Faculty of Logistics and Crisis Management Studentské nám. 1532, 68601, Uherské Hradiště, Czech Republic

E-mail: kvichova@utb.cz

ORCID: 0000-0003-3420-9411

doi: 10.7441/dokbat.2019.022 